\title{
Waste Management Statistics in the Czech Republic
}

\author{
Egor Sidorov $^{1,2}$, Iva Ritschelová $^{1,3}$, and Jiří Hřebíček ${ }^{4}$ \\ ${ }^{1}$ Czech Statistical Office, Na padesatem 81 , \\ 10082 Prague 10, Czech Republic \\ iva.ritschelova@czso.cz \\ ${ }^{2}$ Jan Evangelista Purkyne University, Faculty of Environment \\ Kralova vysina 3132/7, 40096 Usti nad Labem, Czech Republic \\ egor.sidorovaujep.cz \\ ${ }^{3}$ Technical University of Liberec, Economic Faculty \\ Voronezska 13, Liberec, Czech Republic \\ ${ }^{4}$ Masaryk University, Institute of Biostatistics and Analyses \\ Kotlarska 2, 61137 Brno, Czech Republic \\ hrebicek@iba.muni.cz
}

\begin{abstract}
History of statistics in the field of waste management in the Czech Republic is relatively long. At present the waste management survey is focused among others at the generation of waste by enterprises and municipalities, methods of waste use and disposal, and other methods of waste management.

The main objecotive of the paper is to introduce the system development and the processing methods. The paper deals not solely with the determination of the set of reporting units and its changes over years, yet also with technology of data processing, system of checks, corrections, and with a description of control relations. Following to the reduction of administrative burden on respondents and reduction of the respondent pool (from 18 thousand to 10 thousand over 5 years), methods for imputations and statistical checks are also presented. The discussion part of the paper is focused at balancing the purpose of waste management data with respective administrative burden related to their production.
\end{abstract}

Keywords: waste, secondary raw materials, statistics, data processing, Czech Republic.

\section{Introduction}

As a part of the State Statistical Service of the Czech Republic (CZ) the Czech Statistical Office (CZSO) aims at acquisition of data and consequent production of statistical information on environmental state of the country among others [1]. Environmental policies both at international and national level lead to the stable demand for high quality environmentally related statistics [2], [6].

Waste management statistics belongs among traditional statistical outputs of the CZSO. Forming an important input for production of the core indicators of environmental and resource efficiency waste statistics is highly demanded by the 
variety of stakeholders that use them both for design and consequent evaluation of environmental, production, trade and other policies at different levels. As an essential decision supporting tool of resource management activities waste management statistics becomes more and more related to policies in the field of secondary raw materials. These processes make waste statistics a matter of strategic interest at national level.

The following paper maps the main milestones that have influenced its recent development of the official waste statistics in $\mathrm{CZ}$ and presents a bottom line of its current state. The special attention is devoted to current processing methods including issues of determination of the set of reporting units, system of checks, corrections, and description of control relations aimed at keeping quality of statistical data and information. Following the political stress at administrative burden reduction the discussion part of the paper is focused at balancing the purpose of waste management data with respective administrative burden related to their production.

\section{Institutional Conditions}

The primary transformation of the Czech economy in the beginning of the 90's was related to variety of activities aimed at improving the environmental state of the country. Czech environmental situation of that time could be rated as one of the most problematic in the Central Europe. In the first half of the 90's the important changes of environmental protection, especially in the legislative sphere, took place. These activities widely stimulated development of environmental statistics including statistics in the field of waste management.

During that period legislation has consequently covered the variety of environmental domains, state institutions and environmental funding processes. In addition to acts establishing the Ministry for the Environment (1989), Czech Environmental Inspectorate and State Environmental Fund (1991) number of environmental regulations either newly appeared, or were updated. These were often inspired and/or stimulated by the European legislative framework.

The initial legislative act in the field of waste was introduced back in 1991. It was a historically first codified text to provide a legislative framework for waste issues in $\mathrm{CZ}$. In reaction to these processes the CZSO has started regular waste generation survey in 1992.

The initial act on waste was valid till the end of 1997, when it was replaced by another act aimed at solving number of conceptual and practical issues of its predecessor. The 1997 version of act declined the special waste category of waste. All the waste was divided into two categories: hazardous and other waste. On the one hand conditions of hazardous waste operation were restricted. On the other hand they were simplified in case of other waste types.

These developments were also closely connected to active preparation of $\mathrm{CZ}$ to entering the EU. During that time the Czech legal regulations transposed several tens of European environmental directives. As a result of these processes the contemporary 
legal framework of $\mathrm{CZ}$ responds to all new legal environmental regulations adopted by the European Community.

At present the waste operation is regulated by the act on waste of 2001 . The reason for its adoption was that compatibility of the former national legislative framework with community law was relatively insufficient. The new act introduced number of updated and totally new definitions, principles, institutes and processes. Today the Czech legislative framework in the field of waste is compatible with waste management laws and regulations of the EU ${ }^{1}$.

All the above mentioned institutional conditions during this time were actively forming demand for high quality waste statistics. These requirements have also been consequently finding respective reflections in the activities of the CZSO. The CZSO environmental department was established in 1993. Its personnel capacity have been fluctuating around 8-9 employees during the whole period of its existence with 2 fulltime persons performing survey in the field of waste management statistics (excluding processing staff.

\section{Waste Survey Evolution}

CZSO has been performing statistical surveys in the field of waste generation and waste treatment since the 80's. Two stand-alone surveys of waste landfills and waste production were initially performed by the former Federal Statistical Office in 1980 and 1987. However, regular annual waste generation surveys have been performed since 1992 [1]. And through the number of existing critiques (e.g. waste type coverage, highly aggregated outputs, etc.) this survey from 1992 established a good basis for further time series creation.

The statistical waste survey is a part of the Programme of statistical survey for the relevant year. Under Act No 89/1995 Coll., on state statistical service, the reporting unit is obliged to provide all the required data. On the one hand for the unit there exists a legal duty to provide the required data to the Federal Statistical Office, but on the other hand the office provides these subjects with a guarantee of protection of the provided individual information. In practice this means that any data about the production of waste, the means of its elimination etc. may be provided to another subject only in aggregated form. This means in a form where it is not possible to identify the producing unit. The provision of information to the Ministry of the Environment (MoE) and its subordinate organisations (for example the Czech Environmental Inspectorate) is no exception. This fact is important in particular for those units which do have a duty under the waste act to keep records on waste, to report data about production and handling of waste to the district authority, but which for any reasons (mainly due to ignorance) do not fulfil this duty.

\footnotetext{
${ }^{1}$ At present the new version of act on waste is being discussed. The main reason for that is the fact that since 2001 the act on waste has been amended number of times in order to implement several mutually independent EU directives and therefore became relatively complicated and disorganized.
} 


\subsection{Statistical Surveys in 1992 - 1997}

In spite of the reservations which existed about the survey - the recording of only part of the issue (category of special and dangerous waste), publication of only aggregated data (with regard to protection of individual data) etc., the data generated at the given time constituted a relatively good basis for the creation of time sequences showing the developmental trends in the area of the production and disposal of a certain category of waste.

The attempt to prevent the duplicate counting of waste (when transferring waste between several subjects) lead to the survey being focussed up to 1994 only on ascertaining the method for the disposal and use of waste at the own facilities of the producer. The interest in the identification of the further flow of waste after its transfer to another unit was the reason for expanding the survey (from 1995) to include the identification number of the organisation to which the given waste is transferred. On the basis of a comparison of the receiving organisations with the register of operators of landfills and incinerators it was possible to identify the elimination of the transferred waste for approximately $60 \%$ of production.

Companies which on the basis of predominant activities were classified pursuant to Czech "Statistical Classification of Economic Activities" [8] (referred to hereinafter as NACE) in sections 01,10 to $41,45,55,601,602,62,747,7481,851,852,90$, 9211, and 93 and with 25 or more workers were included in the statistical survey. From the start the statistical survey was performed using the enterprise method, i.e., the data relates to the headquarters of the company.

No significant changes were made in the survey in 1997 either. One of the most significant changes was an expansion in the survey to include the anticipated means for elimination or use of waste at the receiving organisation.

More than 70 of statistical statements were returned, and there is a slight ongoing increase.

\subsection{Statistical Survey of Year 1998}

1998 was a year of very extensive changes in the area of waste statistics. The statistical survey of production and elimination of waste was adapted as far as possible to the new Waste Act 125/1997 Coll. and its implementing decrees. The main changes in the survey included:

1. switch to new waste catalogue [9];

2. switch to new system for codifying the methods for the disposal and use of waste;

3. inclusion of category "other waste" in survey;

4. expanding set of respondents.

On the basis of discussions with respondents about these changes, and on the basis of the testing of the statement, it was seen that changes No 1 and 2 caused the greatest problems. The new system for codifying the methods of disposal and use of waste in particular is considered relatively complicated. 
From the aspect of the statistical survey there occurred significant problems in subjects where at the time systematic attention had been paid to waste management and they had the records adjusted on the basis of the new rules. But in addition to these subjects there existed hundreds and thousands of smaller subjects for whom it was very difficult to understand the new regulations and fill in the statistical statement.

The switch to the new waste catalogue [9] was a very difficult matter not only for the respondents themselves, but also for those processing the survey. From the aspect of simplifying this switch a conversion key between the old and new catalogue was created. This conversion bridge made it possible to preserve and prolong the timelines concerning the production and disposal of special and dangerous waste which at the time were of relatively high quality. It unified and simplified the conversions for the respondents themselves, and last but not least it at least in part preserved the possibility of checking information provided by the respondent.

The set of respondents was the same as in the previous period, i.e., companies which on the basis of predominant activities were classified pursuant to "Statistical Classification of Economic Activities" (referred to hereinafter as NACE) in sections 01,10 to $41,45,55,601,602,62,747,7481,851,852,90,9211$, and 93 and with 25 or more workers were included.

\subsection{Statistical Survey 1999-2012}

In general terms it can be stated that in view of the above specified set of respondents it is evident that it was not possible to interpret the gained results as the overall volume of produced waste in $\mathrm{CZ}$, but as its decisive part.

Up until 1998 no calculations of production which were common in EU countries were implemented. In 1999 for the first time a rough estimate was made for the total production of dangerous waste based on the methodology of the European Statistical Office. The calculations were based on the industry classification of waste producers, their size (according to the number of workers) and volume of their production. ${ }^{2}$

In the period 1999-2001 there were no significant changes in the organisation of the survey, but in 2002 a special section was introduced for ascertaining municipal waste from towns which the regular annual reports of this indicator to Eurostat followed on from [6].

2 The analysis of production of waste according to size of enterprise (number of workers), according to production of enterprises and according to volume of annual waste production is relatively interesting and, from the aspect of imputations, essential. For example in 1996 enterprises with up to 50 workers contributed only $2 \%$ to the production of special and dangerous waste, but in the set of respondents it was virtually $28 \%$ of the surveyed enterprises. The analysis of the set of respondents from the aspect of volume of their production of waste showed that more than $95.3 \%$ of the ascertained volume is generated by less than $3 \%$ of respondents producing more than 6000 tons of special and dangerous waste per year. $74 \%$ of the enterprises surveyed produce less than 150 tons per year, and $12 \%$ produce between 150 and 500 tons per year. 
After five years, in connection with attempts to simplify the survey, in 2007 a unified form for towns and the corporate sector was introduced.

In 2008 a selected set of respondents was switched to the new classification CZNACE Rev. 2 [10], which was prepared by the Czech Statistical Office in compliance with Regulation (EC) No 1893/2006 of the European Parliament and of the Council of 20 December 2006.

The surveyed data is classified according to groups of the official waste catalogue among others [11]. The survey covers data on waste generated by enterprises (broken down by hazardous and other waste), waste generated by municipalities (including separately collected categories), waste management (recovery, disposal, etc.).

Another significant change was the change in the technology for selection of respondents for the corporate sphere in 2009, when a so-called "rotation" survey model was introduced (for more details on this model see below).

So far the last change which occurred in 2011 was the introduction of a survey into secondary raw materials [4]. This change occurred as a result of the amendment of Act No 154/2010 Coll., the Waste Act No 185/2001 Coll.

\section{$4 \quad$ Technology for Processing of Statistical Survey}

The actual technical processing of the filled in and collected statements is a highly complicated matter. For more than twenty years the Czech Statistical Office has been using the so-called ProjektMan software. This software is intended for the support and automation of project work on statistical statements. It allows the interactive drafting of sections, the assembly of statements using these sections, the assembly of parts of statements and supra-statements and the creation of projects above these statements and supra-statements.

The information administered by the ProjektMan system can then be used to assemble tasks and check runs in the DataMan system for data acquisition and the EPV electronic reporting system. ProjektMan can be run on PCs using the operating system MS-Windows. The minimum system requirements for ProjektMan include a Pentium class processor with frequency of at least $1 \mathrm{GHz}$ and $256 \mathrm{MB}$ RAM.

The technology for processing the survey is described in the so-called technical project [5]. The technical project includes, amongst other things, the following information:

- Timetable for preparation and processing of entire survey;

- Coordination of all involved offices of the CZSO;

- Description of primary input data;

- Description of processing technology;

- Description of checks, corrections, autocorrections and derived indicators;

- Definitions of outputs.

With a view to current version of the statistics act respondents have an option of filling-out the survey both in electronic as well as in paper form. Electronic survey 
tools include editable .pdf forms and electronic survey software that is available free of charge online on www.czso.cz.

\subsection{Data Collection and Processing}

Data collection and survey processing is performed in a centralized manner with common procedures of checks, corrections and control relations. Data verification takes place right after survey processing. In case of discrepancies evaluation procedures are in place. In case of necessity, discrepancies may be additionally checked with respective respondents. Centralization of these procedures enables significant reduction of input data verification time. The necessary condition is full survey completion by the unit.

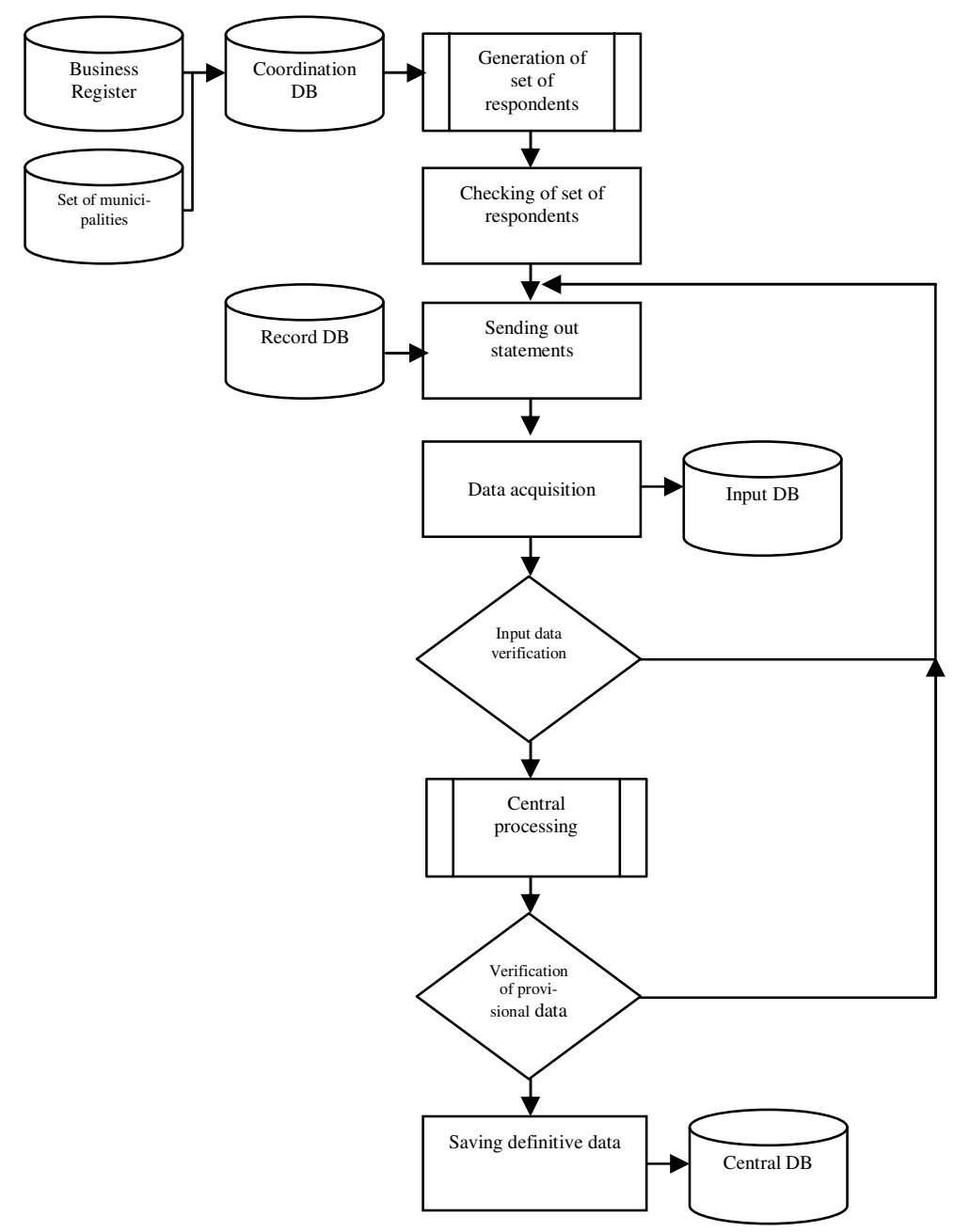

Fig. 1. Principal Survey Processing Scheme [Source: own construction] 
The generated set of respondents passes via the coordination database and is also made accessible to the environmental statistics department for checking and agreement ( $\mathrm{T}^{3}-10$ months), which is then followed by the sending out of electronic forms (or paper forms, if the respondent has no data box) (T-9 months), data acquisition ( $\mathrm{T}$ 7 months), its input verification and uploading (T-4 months). After the end of gathering the data is sent to the central processing department, where so-called provisional data is generated (T-3 months). This is then subject to further checks, but not now from the aspect of the individual respondents but from the aspect of the entire set.

Any fluctuations and inconsistencies in waste data are traced back to the level of an individual respondent, with whom a verification of the reported data is initiated via the statistical processing department, or the data is immediately amended. In this way definitive data is gained, which is locked and saved to the central database (T-1 month), which is a data source for all publication outputs and public presentations of data for national and international needs.

\subsection{Data Verification}

In the course of processing of the statements there is verification, amongst other things, of the correctness of the data given by respondents via several tens of check links. After the discovery of any doubts the unit is contacted by workers of the statistical office, and they attempt to resolve the problem together. It is necessary to state that after many years of experiences with this survey the communication with respondents is constantly improving, as is their willingness to cooperate.

In the context of the data processing logical methods for the analysis and checking of all output indicators from various aspects are developed. The following 5 groups of methods for logical checks and links of indicators can be distinguished in the context of the individual statements:

- Relationship to identification of respondent unit;

- Relationship to classifications and code lists;

- Relationship to completeness of filling in of questionnaires;

- Empirical checks.

With regard to the identification of the relevant respondent unit it is possible to name logical checks focussing on the completeness and accuracy of specification of respondent identification data from the aspect of the formal requirements (for example, number of business ID No ${ }^{4}$ symbols) and material accuracy (for example, presence of business ID No in Business Register of CZ [12] and/or presence of business ID No in selected set).

Logical checks in relation to classifications and code lists are performed from various aspect (for example according to the classification CZ-NACE [10], according to code lists of types of waste according to the Waste Catalogue [11], according to the waste category or, for example, the method of handling [13]). Logical controls

\footnotetext{
${ }^{3}$ T denotes September 30 of given year.

${ }^{4}$ ID No is the unique 8 number of identification of business unit in the Czech Republic.
} 
focus primarily on the generation of impermissible codes in compliance with the classifications and code lists.

From the aspect of completeness of filling in of questionnaires, checks are performed focussing on the completeness of filling in of the individual lines (for example, if on a given line a certain item is filled in, the other relevant items in the line must be filled in). In addition many checks are based on the balance principle (for example, whether the amount of waste recorded as transferred waste is equal to the amount of waste recorded as received waste, whether the sum of the individual categories is equal to the value of the category of higher degree). The check sums represent a highly significant tool for checking the completeness of correctness of the filling in of the statement. Incorrect check sums are given including the relevant differences.

Empirical checks focus primarily on the logical interconnectedness and justifiability of the statements' individual elements in relation to the legal standards, methodological instructions and experience with collection of data from the preceding periods. For example, in view of the fact that the import of waste to $\mathrm{CZ}$ with the aim of dumping is forbidden, for the given type of waste according to original the handling code characteristic for storage was given. One example of a check from the methodical aspect is the linkage of definitions of waste and secondary raw material. If production of the recorded waste is identical with the amount of recorded production of secondary raw materials, this is probably an error, because in view of the methodology of the statement it is not possible to record the material flow in both sections of the statement. Many checks are associated with the fact that a certain means of handling is only possible in the case of certain waste codes. In addition, for example, in the case of a town there is an expectation that the part of the statement associated with municipal waste will be filled in. Empirical experience also makes possible a check on the presence of extreme values (for example, volume of municipal waste per inhabitant). Frequent errors include not giving the name and address of the firm taking the waste.

The most basic checks include a comparison of the specified production and method of waste disposal with the production and disposal declared in the preceding years. And this comparison helps to identify many errors which the respondents make. This involves in particular incorrect recording or recording of significantly lower or exactly the same production as the preceding period.

On the basis of experience, the following errors constitute other frequent errors in the area of the statistical survey:

1. mixing up units of measurement (for example, kilograms confused with tons and vice versa);

2. incorrectly selected physical indicators (instead of weigh units, volume units or items are given);

3. impossibility of making estimate (if the respondent itself is not capable of making a qualified estimate of weight, the workers of the statistical office help him with the estimate on the basis of previous experience; this involves, for example, the weight of strip lights, rechargeable batteries, content of sumps, sludge from riverbed maintenance, sedimentary water from sludge settling ponds etc.); 
4. incorrectly selected financial indicators (for example, costs for waste removal are given differently with or without VAT).

In addition to the calculation of absolute values the analyses also contain an evaluation of the relevant indicators (so-called, provisional indexes). For these purposes in the phase of verification of provisional data so-called check tables are generated in the specified structure mainly allowing a comparison of the data recorded by individual respondents over time. The check focuses on units displaying a significant year-on-year increase (index >150) or dropped (index <50) in the investigated indicators. Attention is also paid to identical year-on-year data.

\section{Generation of Basic Set}

The set of survey respondents then consist of both legal persons and trading natural persons and towns. In compliance with Regulation (EC) No 2150/2002 on waste statistics the method of selective survey is used in order to minimize the burden on respondents [13].

Economic subjects are selected from a set of all possible respondents from the Business Register [11]. The Business Register plays the role of integrated statistical instrument which is regularly updated and in which the basic characteristics of the subjects allowing stratification and parametric selections are kept. All subjects in the Business Register are unambiguously designated by the identification number of the legal or natural person.

\subsection{Criteria for Generation of Basic Set}

The basic set of the CZSO survey in the area of enterprises in a general case includes economic subjects classified in the sectors S11, S13 and S15 of CZ NACE [10]. The concrete criteria for the generation of the basic set are as follows [5]: enterprises in context of CZ NACE codes 01-36, 451, 452, 47, 491-494, 55, 56, 59, 611-612, 96019603 with number of employees greater than 25; CZ NACE codes 41-43, 742, 812, 813 with number of employees greater than 20; CZ NACE code 4675 with number of employees greater than 5; CZ NACE codes 37, 38, 39, 4677 with zero number of employees and CZ NACE codes $86,871-873$ with number of employees greater than 50 .

For the purposes of ensuring the necessary level of quality of the statistical outputs, some selected enterprises (so-called core enterprises) are also surveyed regardless of the number of employees. This involves about 300 firms which as the most significant waste generators with almost three quarters of the total amount of all produced waste in the country.

In order to reduce reporting burden the so-called "rotation model" approach to respondent selection has been used since 2009. It consists in regular surveying of the most significant business entities (according to generated waste, industry type, or pursuant to the number of employees). The remaining "rotation" part of respondents 
is inquired once every three years with the rest of the data being mathematically imputed. This approach enabled reducing of respondent number by almost a half.

Core and newly formed enterprises are selected for the selection set from the basic set. The remaining firms from the basic set are divided up into three thirds, of which only one third gets into the selection set for each year of the survey.

Sets of respondents also go through a so-called coordination database. This is a tool developed under the conditions of the CZSO making it possible to include the given economic subject in the current year in the minimum necessary number of statistical surveys (naturally with regard to its importance).

In the case of municipalities there is a systematic selection of the pre-designated number of units with randomly selected start stratified according to regions at the level of NUTS2 [14] and number of inhabitants in the municipality [5]:

1. up to 200 inhabitants;

2. 200-999;

3. $1000-9999$;

4. 10 000-99 999;

5. above 100000 .

In context of the given rotation cycle municipalities selected for survey in the preceding year and belonging to strata 1.-3. have been excluded. Using this additional selection the change of sets is ensured, and in the given year the selected units are then assigned a new order of change, and the existing order of change of the remaining units in the selection set is reduced by 1 . It should be noted that in the case of strata 4 . and 5 . there is a blanket survey.

For the purposes of a reduction in the administrative burden of municipalities, mathematical-statistical imputation methods are used as part of the survey of municipal waste production. For the purposes of imputation at least 5 filled statements are required in each stratum. In the case of stratum 2. and 3., 80\% response is required, for stratum 4. it is $90 \%$, and for municipalities in excess of 100000 inhabitants a $100 \%$ response is required. It must be noted that the accuracy of the calculated results at the level of NUTS2 [14] even in the case of a 100\% response the incidence of extreme values may not wholly satisfactory in view of great spread of calculated data [5].

\subsection{Brief Characteristics of Computation Procedure}

The scope of the basic set from the enterprise sphere is considered final without the need for further calculations. The data gained for municipalities is then calculated for the entire Czech Republic.

With regard to municipal waste, for the municipalities the calculations are made on the basic set of all municipalities of $\mathrm{CZ}$ and this is only on the basis of values filled in for the relevant year. The calculation is performed in the following manner: the acquired data for the individual variables is multiplied by the designated weightings, and the weightings are the same for all variables. 
The calculation of weightings is performed in compliance with the separation of municipalities into regions according to size groups (strata). Weightings are estimated as the share of all inhabitants permanently living in the strata out of the number of inhabitants for the municipality with a filled in statement. Three values of weightings are distinguished:

1. weighting $=1$ for external units ${ }^{5}$ and in a general case municipalities with a number of inhabitants in excess of 100000 ,

2. non-zero weighting $(>1)$ for other municipalities with filled in statement,

3. zero weighting for units not included in selection.

In compliance with the technical project [5], if in the given stratum extreme values are identified with the weighting $=1$, the weighting of the other non-extreme municipalities in the same stratum is increased in such a way that the sum of weightings multiplied by the number of inhabitants for the municipalities to whom a statement has been sent out in the given year in the given stratum is equal to the total number of inhabitants in the given strata.

As has been stated above, for the calculation of weightings for the individual to be possible and reliable, there is a requirement that in each stratum there should be at least 5 non-extreme municipalities with filled in statement. If the given conditions are not met in some stratum, a calculation of weightings is conducted for the larger strata ( 2 size groups of municipalities are merged into one). But this procedure reduces the accuracy of the calculation. As a priority the minimum number of filled in statements is ensured by sending reminders to respondents [5].

\section{Balancing Users Needs and Reporting Burden Optimization}

The official purpose of the survey proclaimed by the CZSO as an institution producing European statistics is the meeting of the duties arising from Regulation (EC) No 2150/2002 of the European Parliament and of the Council of 25 November 2002 on waste statistics, Directive 98/2008 of the European Parliament and of the Council of 19 November 2008 on waste and repealing certain Directives, for the purposes of the European Union (EU) and international organisations [15-17], in particular the Organisation for Economic Cooperation and Development (OECD) [18], and to give information to the public .

Among the major international user categories one can name e.g. Eurostat and its data users representing all EU member states and other countries. For more than a decade the CZSO has been transferring waste related data to Eurostat. During 19952004 the national data reporting was performed according to the so-called Eurostat/OECD Joint Questionnaire on Waste. After Regulation (EC) No 2150/ 2002 of the European Parliament and of the Council of 25 November 2002 on waste

\footnotetext{
${ }^{5}$ A municipality where the share of the value of the reference indictor to the number of permanently resident inhabitants is more than 20 times higher than the average share of the value of the reference indicator to 1 inhabitant in the given stratum is considered to a an extreme unit.
} 
statistics, the national administrator of which is the Czech Statistical Office, Eurostat is sent data about waste in the format designated by Commission Regulation No $782 / 2005$. In compliance with the given regulation the data which was originally classified according to the Waste Catalogue has been transformed into the required classification EWC-STAT (into the so-called statistical nomenclature of waste focussing on the main substance contained in waste) and in the following structure [13]:

- production of waste in classification pursuant to EWC-STAT [13] and CZ-NACE Rev. 2 [10] in classification pursuant to category of waste "dangerous" and "other" waste, level NUTS0 [14];

- handling of waste in classification pursuant to EWC-STAT and pursuant to selected codes of handling R and D, level NUTS0;

- numbers of devices for use and disposal of waste and their capacity, level NUTS2.

With regard to data about the production and handling of municipal waste, this has been sent to Eurostat every year since 1995 for the purposes of evaluating the Structural indicator on Municipal waste [19]. The methodology for the collection of data complies with the instructions in for the OECD and Eurostat questionnaire about municipal waste. The respondent units are the municipalities which ensure that waste produced by subjects integrated in the municipal system of waste collection, such as schools, government offices and small businessmen, is also included in the survey ${ }^{6}$.

Among the main data users directly using data on waste are e.g. such national institutions as Ministry for the Environment and its affiliate Czech Environment Information Agency (CENIA), Ministry of Industry and Trade (MIT), variety of research and development institutions and, of course, media. The calculation of indicators for material flows in cooperation with Charles University in Prague (Environmental Center) is just one well-known means of use of the outputs from the statistical survey [20], [21].

The data about secondary raw materials is intended directly for the needs of the concrete institutional user in the shape of the Ministry of Industry and Trade as the basis for strategic and analytical document for the area of use of secondary raw materials pursuant to government resolution No 1398/2009.

Monitoring of secondary raw materials represents the most significant change of the survey of the last years. This change reflects the latest political and economic conditions when producers are highly motivated to transform waste (i.e. negative production) into secondary raw materials and to actively use them as production inputs.

Issues of raw materials safety are paid an exceptional attention at the European level at present. Secondary raw materials are looked at as a strategically important input into production process. Under these circumstances one can expect that extended waste (and secondary raw materials) production survey would be consequently improved and developed in future according to various stakeholder needs.

\footnotetext{
${ }^{6}$ The statistical data of the CZSO does not include municipal waste produced by legal persons and natural persons authorized to trade who are not included in the municipality's municipal waste management system.
} 
The flexible nature of the statistical survey [20], which is implemented on the basis of an annually approve programme of statistical survey, is not a priori bound by complicated processes for the passing legal regulations and allows the CZSO to react flexibly to the requirements of statistical users. For instance, in CZ the waste related data is also being currently provided from an administrative source by the Ministry for the Environment through Integrated system of reporting compliance at CENIA. However, since its actions are limited by the waste-related legislation, and novelization processes involving number of stakeholders are difficult and time consuming, the Ministry for the Environment has no power to follow the new material flow trends so operatively. This also highlights flexibility of national statistical office in reflecting current socio-economic reality.

The collected data is a part of number of regular publications such as Statistical Yearbook of CZ, Generation, Recovery and Disposal of Waste in CZ [20], Statistical Environmental Yearbook of CZ [22], and Report on the Environment of CZ [23] among others. The last two are joint outcomes of CZSO and the Ministry for the Environment.

One should expect, however, that the range of possible data users is far more extensive. Since the CZSO publishes the majority of data on its web pages, significant amount of regular data users remain anonymous, since they obtain them indirectly via internet.

High-quality and easily accessible information is the key to the correct and effective decision-making and implementation of environmental policy and waste management instruments. Data to evaluate the status of waste management come largely from public resources available [21-23]. Any additional information are used for comparison or detailed descriptions of phenomena that are not tracked in CZSO public statistics. They are based on functional, up-to-date and credible information resources of CZSO and MoE, CENIA, MIT describing the status of waste management in CZ, operated within a defined legal and information environment of CZSO.

The CZSO is preparing data and information outputs for the needs of the MoE, other ministries and the Government of CZ. In addition, it satisfies the reporting requirements of Eurostat and this data and information are used by the European Commission, DG Environment and the European Parliament. Quality of the information obtained from statistical surveys is ensured by internal standards of CZSO compatible with Eurostat.

Range of possible waste statistics outputs is closely related to methodological peculiarities of their production. One should mention that the range of possible waste statistics uses is objectively limited by legislative requirements on the one hand and financial perspective both on the side of respondents and CZSO on the other.

The development in the scope of the survey or the number of respondents over the period of the existence of the statement is characterised by the overview given in Table No 1.

Table 1. Waste Production Survey Respondent Base [Source: CZSO]

\begin{tabular}{|l|c|c|c|c|c|c|c|c|c|}
\hline Year & 1993 & 1995 & 1998 & 2002 & 2004 & 2006 & 2008 & 2010 & 2012 \\
\hline No. of respondents & 5820 & 10816 & 14461 & 17741 & 19085 & 17875 & 17363 & 8466 & 10369 \\
\hline
\end{tabular}


As one can see, the change in the technology of selecting respondents implemented in 2009, when the so-called "rotation model" was introduced, was a truly significant change. This resulted in the administrative burden being almost halved.

The aim of the state statistical service is to produce high quality and consistent data on development trends in a given area. According to their nature statistical data is only valid for producing aggregate outputs and according to law cannot under any circumstances be used for administrative or control activities. The aforementioned technology for the collection of data in combination with the methods for imputation for the entire population guarantees the year-on-year comparability of data and allows the use of the gained data to designate trends of the monitored indicators without the results being influenced by the number of included units. Moreover the design of the statement and use of the line of check links significantly prevents duplicity in the entry of the statement in the processing system. And the linkage with the register of economic units plays an irreplaceable role for gaining statistical data with all the attributes of quality.

With respect to above mentioned properties waste statistics information can be used both for designing environmental policies at the national level, as well as its consequent assessment. Waste production dynamics is capable of indicating critical fields where interventions of the state planner are necessary. The same data may be consequently used for assessing efficiency of respective environmental policy measures based on number of benchmarks available in comparable time series.

Waste statistics data produced by the CZSO based on EU-wide common methodological basis can be applied as an environmental management tool also at international level [15-18]. For instance, they can be used for benchmarking of country performance and achievement of different policy goals in comparison with other member states.

Concerning information needs of the regional policies one can state that this is one of the weaknesses of the statistical survey on waste. Regional policy is primarily aimed at programs at the level of administrative regions' falling under respective executive bodies. One also cannot exclude user requirements for data about of non-administrative, i.e. functional regions. With respect to survey methodology one can find several objective shortcomings that disable production of regional statistics (e.g. [24] in Czech).

From the legislative point of view survey methodology fits the requirements of relevant EU regulations. As it was mentioned above European legislation requires data reporting at the CR (i.e. NUTS0) level, without any need for data regional decomposition. This is directly related to the objective needs of the European executive power data needs. It is also an outcome of active administrative burden reduction policy both at the EU and national levels. Given additional saving measures that are being made by the government the waste survey is designed in a way to satisfy only mandatory legal EU requirements. These features are directly related to a limited extent of respondents and application of rotation and imputation techniques that enable production of required quality outputs at the national level, and not at regional level though.

Another reason for regional data absence is the applied method of data collection. According to methodology indicators are surveyed based on the so-called enterprise method that allocates respondent data according to headquarters geography and not 
according to respective local units. In this respect regionalization may be accompanied by significant distortions of waste production geography (e.g. establishment with local production unit in one of the regions and headquarters located in the capital city may indicate e.g. production of waste in the capital city where no pollution production actually takes place). Such input data cannot be used for production of quality regional waste statistics. Only municipal waste data is relevant at the regional level, since one can directly allocate municipalities to the specific region.

In order to produce data that would be valid at the regional level the current enterprise method should be replaced. E.g. companies could fill-out as many surveys as many regions they operate in. Number of respondents in this case would remain the same, however total administrative burden would increase. This approach is however related to the possible double counting issue related to common practices of transporting waste materials between the local units.

\section{Conclusion}

Waste management data collection technology combined with imputation methods enables inter-temporal comparability of data in EU and its use for setting of development trends of the Czech Republic in compliance with EU. Waste statistics outputs provide the whole range of institutional users a valuable information base for environmental policy design and its consequent assessment both at national, as well as international levels.

At present the statistical survey method is primarily based on requirements of EU legal acts in the field of waste statistics. The limited survey extent is also highly influenced by administrative burden reduction and cost saving policies of the government. These are objective factors that disable production of outputs at the regional level. Given the institutional demand and more favourable economic conditions the flexible nature of the statistical survey, however, doesn't exclude the possibility of adaptation of survey design to ever-changing needs of decision-making sphere.

Acknowledgements. This paper is a result of the project of Technology Agency of the Czech Republic No. TD010130 Regionalization of economic performance indicators in relation to environmental quality. The support is gratefully acknowledged.

\section{References}

1. Ritschelova, I.: Determinantion of Waste Production in CR. Eurostat - Work session on environmental statistics, Lysebu - Norway, Working Paper No. 13 (1996)

2. Ritschelová, I., Sidorov, E., Hřebíček, J.: Environmental Statistics at the CZSO: Past Development and Future Trends. In: Hřebíček, J., Schimak, G., Denzer, R. (eds.) ISESS 2011. IFIP AICT, vol. 359, pp. 33-46. Springer, Heidelberg (2011)

3. Ritschelova, I., Sidorov, E., Farsky, M.: Impact of Waste Deposition Fees on Enterprises in the Czech Republic. E\&M Ekonomie a Management, 2 (2010)

4. CZSO. Generation, Recovery and Disposal of Waste 2011. CZSO, Prague (2012) 
5. CZSO. Technical Project of Collection, Processing and Data Presentation in CZSO Odpady 5-01 for 2012 (Technický projekt sběru, zpracování a prezentace dat v resortu CSÚ. Odpady 5-01 za rok 2012). Prague, CZSO (2012)

6. EUROSTAT. Quality in the European statistical system - the way forward. Luxembourg: Office for Official Publications of the European Communities, (2002), http: / / epp. eurostat. ec. europa.eu/portal/page/portal/quality/ documents / ESS_QUALITY_RECOMMENDATIONS_2002_EN_0_1.pdf

7. CZSO. Statistical surveys of the CZSO. CZSO, Prague (2012), http://www.czso.cz/eng/redakce.nsf/i/statistical_ surveys_of_the_czso

8. CZSO, http://www.czso.cz/csu/klasifik.nsf/i/odvetvova_ klasifikace_ekonomickych_cinnosti_ะ280kec\%29

9. Decree of the Ministry of Environment, issuing waste catalogue and provides other lists of waste (Waste Catalogue) 337/1997 Coll., Prague, Ministry of Environment (1998)

10. CZ-NACE, http://www.czso.cz/eng/redakce.nsf/i/classifications

11. List of waste, http://eur-lex.europa.eu/smartapi/cgi/sga_doc? smartapi ! celexplus ! prod! CELEXnumdoc\&numdoc $=32000 \mathrm{D} 0532 \& 1 \mathrm{~g}=\mathrm{en}$

12. Business Register, http://www.czso.cz/eng/redakce.nsf/i/business_ register

13. European Waste Classification for Statistics, version 4, http://ec.europa.eu/eurostat/ramon/other_documents / ewC_stat_4/index.cfm?TargetUrl=DSP_EWC_STAT_4

14. CZ NUTS, http://notes.czso.cz/csu/klasifik.nsf/i/klasifikace_ uzemnich_statistickych_jednotek_o28cz_nuts\%29

15. EIONET, http://scp. eionet. europa. eu/facts/wastebase

16. DG Environment, http://ec.europa.eu/environment/waste/publications/

17. EEA, http://www . eea . europa. eu/themes/waste

18. OECD, http://www. oecd.org/env/waste/

19. EUROSTAT. Sustainable development indicator on municipal waste. How to deliver data, http: / / epp. eurostat. ec. europa.eu/portal/page/portal/waste/do cuments/Guidance_document_on_Municipal_Waste_2011.pdf

20. CZSO. Statistical Yearbook of the Czech Republic 2012. CZSO, Prague (2013), http: / /www.czso.cz/csu/2012edicniplan.nsf/engkapitola/ 0001-12-eng_r_2012-0300

21. Kovanda, J., Weinzettel, J., Hák, T.: Material Flow Indicators in the Czech Republic in Light of the Accession to the European Union. Journal of Industrial Ecology 14, 650-665 (2010)

22. Statistical environmental yearbook of the Czech Republic 2011. CENIA, Prague (2012), http: / / www.cenia.cz/rocenka2011/index.htm

23. CENIA, Report on the Environment of the Czech Republic (2011), http: / /www1.cenia.cz/www/sites/default/files/ Report_on_the_Environment_of_the_Czech_Republic_ 2011_pro\%20web\%20a\%20USB.pdf

24. Statistical survey South Moravia region (Statistická ročenka Jihomoravského kraje (2012), http: / /www.czso.cz/csu/2012edicniplan.nsf/krajkapitola/64101 1-12-r_2012-03 